\title{
Prediction and Trends of Rainfall Variability over Bangladesh
}

\author{
Mohammad Anisur Rahman*, Sunny Mohammed Mostafa Kamal, Mohammad Maruf Billah \\ Department of Mathematics, Islamic University, Kushtia, Bangladesh \\ Email address: \\ anismathiu@yahoo.com (M. A. Rahman), kamaliubd@yahoo.com (S. M. M. Kamal), marufmath0317@gmail.com (M. M. Billah) \\ * Corresponding author
}

\section{To cite this article:}

Mohammad Anisur Rahman, Sunny Mohammed Mostafa Kamal, Mohammad Maruf Billah. Prediction and Trends of Rainfall Variability over Bangladesh. Science Journal of Applied Mathematics and Statistics. Vol. 5, No. 1, 2017, pp. 54-59. doi: 10.11648/j.sjams.20170501.18

Received: January 3, 2017; Accepted: January 19, 2017; Published: March 1, 2017

\begin{abstract}
Rainfall is one of the most common natural disasters in Bangladesh which rigorously affect agro-based economy and people's livelihood in almost every year. The main objective of this study is to examine the variation, prediction and trend of rainfall in Bangladesh. The data for this study have been extracted from the Bangladesh Meteorological Department (BMD). Data used in this study were collected from 31 rain gauge stations located in different parts of the country for a period of 40 years (1975-2014). Linear regression model is used to understand the variation, trend and prediction of rainfall for annual and various climatic seasons such as pre-monsoon, monsoon, post-monsoon and winter. We also estimated mean rainfall with standard deviation of pre-monsoon, monsoon, post-monsoon and winter. Finding reveals that, the trends of mean rainfall of annual, pre-monsoon and winter have decreased, whereas rainfall remained unchanged in monsoon season and has increased in post-monsoon. Data predicts lesser rainfall in the period 1975, 1989, 1992, 1994, 2004, 2009, 2012,2013 and 2014 years. These results indicate lesser precipitation in future over Bangladesh. The predicted rainfall amount from the best fitted model was compared with the observed data. The predicted values show reasonably good result. Thus the model can be used for future rainfall prediction. It is expected that this long term prediction will help the decision makers in efficient scheduling of flood prediction, urban planning, and rainwater harvesting and crop management. Classification of rainfalls in a systematic way is therefore critical in order to take necessary actions toward drought mitigation and sustainable development.
\end{abstract}

Keywords: Rainfall, Variability, Prediction, Trend, Regression, Bangladesh

\section{Introduction}

Climate change and global warming are recognized worldwide as the most crucial environmental dilemma that the world is experiencing today [1-3]. Concern regarding climate change and global warming by the international community, non-government organizations and governments has brought great interest to the meteorologists on climate trend detection at global, hemispherical and regional scales $[4,5]$. Bangladesh is located between $20^{\circ}$ to $26^{\circ}$ North and $88^{\circ}$ to $92^{\circ}$ East. Even though Bangladesh is a small country with a size of $147340 \mathrm{~km}^{2}$, inter-regional climatic differences in this flat country is not minor. Furthermore, the climate of Bangladesh is greatly influenced by the presence of the Himalayan mountain range and the Tibetan plateau in the north, the Bay of Bengal in the south. The eastern and northeastern parts of the country are wet, whereas the central and western parts are dry. Four distinct climatic seasons can be recognized: (i) dry winter (December-February), (ii) premonsoon (March-May), (iii) monsoon (June-September), and (iv) post monsoon (October-November). Rainfall in Bangladesh is not uniform throughout the country. On average, the northwest part of the country receives about $1,400 \mathrm{~mm}$ of rainfall every year and the northeast receives more than $4,400 \mathrm{~mm}$ of rainfall. More than $75 \%$ of the rainfall in Bangladesh occurs during the monsoon season [6]. It is the country where economy is largely depends on agriculture. The impact of low and high precipitation is very important for agricultural production. Livestock and human ecology depends on the water system especially rainfall. Drought of different intensities occurs across Bangladesh. Rice and other crops productions are severely affected by dryness. To make better understanding of rainfall system 
which can help the formulation of policies that might include preserve and an efficient use of rainfall water in near future. In order to implement a better policy, the policy makers especially farmers need to know the future state of amount of rainfall. Since in all weather happenings, rainfall plays the most imperative role in human life. Human civilization depends to a great extent upon the frequency and amount to various scales of rainfall [7]. The rainfall of Bangladesh is mainly governed by the activities of monsoon system, tropical cyclonic disturbances, local land origin weather systems and sub-tropical western disturbances [8]. Prediction of rainfall is still a huge challenge to the climatologists. It is the most important component of a climate system. Most of the burning issues of our time like global warming, floods, draught, heat waves, soil erosion and many other climatic issues are directly related with rainfall. Agriculture is still the main source of economic activities in the most of the developing countries of the world like Bangladesh. In order to increase crop production and protecting crops, human life, and ecosystem, there is an increasing demand from the policy makers for a reliable prediction of rainfall [9].

Several researchers studied the variability and trends in rainfall across the world. Nicholson observed that one of the most important contrasts in rainfall is the multi-decadal persistence of anomalies over northern Africa [10]. Nicholson and Grist had identified several changes in the general atmospheric circulation that have accompanied the shift to drier conditions in West African Sahel [11]. Rainfall variability in southern Spain on decadal to centennial time scales were studied by Rodrigo and his colleagues [12]. Rotstayn and Lohmann showed a prominent feature is the drying of the Sahel in North Africa and suggest that the indirect effects of anthropogenic sulfate may have contributed to the Sahelian drying trend [13]. Murphy and Timbal reported that most of the rainfall decline has occurred in Autumn (March-May) in southeastern Australia [14]. A similar rainfall decline occurred in the southwest of Western Australia around 1970 that has many common features with the southeastern Australia decline. Nicholls and Lavery reported that summer rainfall over much of eastern Australia increased abruptly around 1950s [15].

Bangladesh demonstrates seasonal alterations with six seasons where natural calamities cause tragic death of lives and severe hazardous in Bangladesh regularly and frequently. It is difficult to predict the weather pattern because of non-linear characteristics of natural disaster and seasonal changes in the country. The conventional weather prediction models are conducting in a huge domain and high resolution in Bangladesh which is constraint to show reliable seasonal disaster predictions [16]. Rahman et al. used trend analysis to study the changes in monsoon rainfall of Bangladesh and found no significant change [17]. Shamsuddin Shahid has analyzed rainfall variability and the trends of wet and dry periods in Bangladesh over the period 1958-2007 using the rainfall data recorded at 17 stations of BMD distributed over the country. The result shows a significant increase in the average annual and pre-monsoon rainfall of Bangladesh. The number of wet months is found to be increased and the dry months are found to be decreased in most parts of the country. Seasonal analysis of wet and dry months shows a significant decrease of dry months in monsoon and pre-monsoon [18]. A number of studies have been carried out on rainfall patterns but only very few works have been found on rainfall trends and extremes in Bangladesh [17-20]. The results of this study may help to drive up the understanding of rainfall variability and prediction of Bangladesh.

\section{Material and Methods}

Data for this study have been extracted from the Bangladesh Meteorological Department (BMD). The BMD collects everyday surface data through weather stations situated at all over Bangladesh. There are 34 old rain gauge stations under BMD in Bangladesh. Of those, 31 stations collected data before 1975. In this study, we used data from 31 rain gauge stations of Bangladesh except Mongla, Chuadanga, Sayedpur and Tangail. The study period is January 1975 to December 2014. It is notable that, there were some missing data in some months. The missing rainfall values are computed by expectation maximization (EM) method. A full description of the EM algorithm can be found in McLachlan and Krishnan [21]. The collected data have been compiled, tabulated and analyzed by MS Excel and SPSSv21 (SPSS Inc., Shicago, IL, USA). Annual and monsoon average of rainfall for different stations are anticipated to analyze the variation and to estimate trend line for the period 1975 to 2014 . The monthly and yearly rainfall data have been obtained from daily rainfall data. The average, standard deviation (SD) and prediction of rainfall in Bangladesh have been estimated from yearly rainfall data.

Regression is a statistical empirical technique that helps in understanding the relation between two or more quantitative variables on observational database so that an outcome variable can be predicted from the others. We used two methods: simple linear regression and multiple linear regression models. Regression produces a polynomial describing the relationship between any set of inputs and corresponding output [22]. The linear regression line has been fitted by commonly used least squares method. This method calculates the best fitting line for the predicted rainfall by minimizing the sum of the squares of the deviations from each simulated rainfall to the line. If a simulated rainfall lies exactly on the straight line then the algebraic sum of the residuals is zero [23].

Residuals are defined as the difference between simulated rainfall at a point in time and the rainfall read from the trend line at that point in time. The simulated rainfall that lies far from the line has a large residual value and is known as an outlier or an extreme value. The equation of a linear regression line is given as:

$$
Y=\alpha+\beta X
$$


where, $Y$ is the predicted rainfall as the dependent variable and $X$ is the simulated rainfall as the independent variable; ' $\alpha$ ' is the intercept of the line on the vertical axis and ' $\beta$ ' is the slope of the line. The estimation of the intercept ' $\alpha$ ' and the regression coefficient ' $\beta$ ' by the least square method is as follows:

$$
\hat{\alpha}=\bar{Y}-\hat{\beta} \bar{X}
$$

and

$$
\bar{\beta}=\frac{\sum(X-\bar{X})(Y-\bar{Y})}{\sum(X-\bar{X})^{2}}
$$

The coefficient of determination,

$$
R^{2}=\frac{\sum(\hat{Y}-\bar{Y})^{2}}{\sum(Y-\bar{Y})^{2}}
$$

In order to fit regression lines, a large number of simulated rainfall (dependent variables) associated with heavy rainfalls are required and plotted. Linear regression line is then fitted to determine the predicted rainfall.

\section{Results and Discussion}

The results of this study on the trends of rainfall over Bangladesh have been analyzed and discussed. Time series data sets are used for this study. Annual, winter, premonsoon, monsoon and post-monsoon mean total rainfall over 31 rain gauge stations of Bangladesh during the 40 years (1975-2014) are discussed below.

\subsection{Trend of Annual Rainfall}

Annual mean rainfall over Bangladesh during the 40 years is shown in Figure 1. The analyses of data depict that the amount of mean annual rainfall for different stations are found to be between $154 \mathrm{~mm}$ to $247 \mathrm{~mm}$ with standard deviations of $41 \mathrm{~mm}$ to $97 \mathrm{~mm}$. In the year 2014, BMD declare that the annual average normal rainfall is $202 \mathrm{~mm}$.

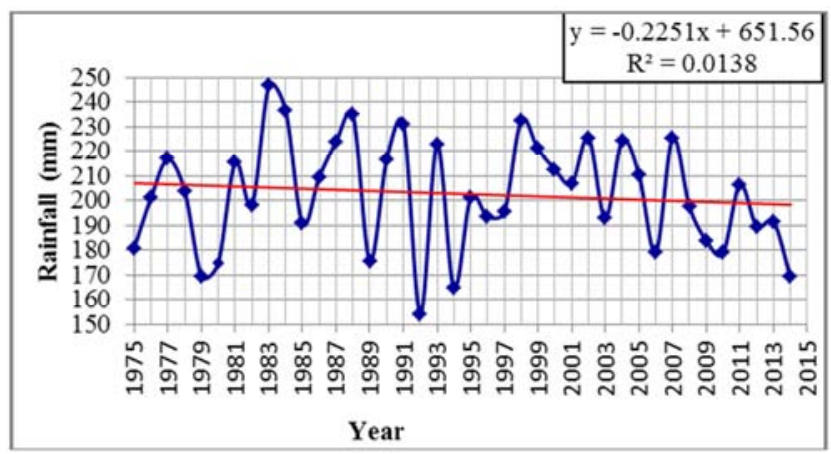

Figure 1. Annual mean rainfall of Bangladesh during 1975-2014.

The analysis reveals that the annual average rainfall of the study are highly lowest from normal rainfall in the years 1975 , 1979, 1980, 1985, 1989, 1992, 1994, 2003, 2006, 2009, 2010, 2012, 2013 and 2014. It is seen from analysis that the rainfall variability of all stations of the study are decreasing and the trend is towards the downward. The observed data and linear trend line shows the decreasing trend of annual rainfall at the rate $0.013 \mathrm{~mm}$ per year in Bangladesh.

\subsection{Trend of Pre-monsoon Season Rainfall}

The mean rainfall of Bangladesh for the pre-monsoon season in the last four decades is shown in Figure 2. We observed that, the mean rainfall of this season for different stations is found to be between $65 \mathrm{~mm}$ to $249 \mathrm{~mm}$ with standard deviations of $41 \mathrm{~mm}$ to $101 \mathrm{~mm}$. According to BMD (2014), the average normal rainfall of that season was $153 \mathrm{~mm}$. Analysis of this study shows that the average rainfall of the study are highly lowest from normal rainfall in years 1975, 1976, 1979, 1982, 1985, 1986 1987, 1989, 1992, 1995, 2003, 2004, 2007, 2008, 2009, 2012 and 2014 for this season. Data also suggest the decreasing trend of the rainfall variability and trend of all stations for the study period. The observed data and linear trend line show the decreasing trend and the pre-monsoon mean rainfall of the Bangladesh rate is recorded as $0.041 \mathrm{~mm}$ per year.

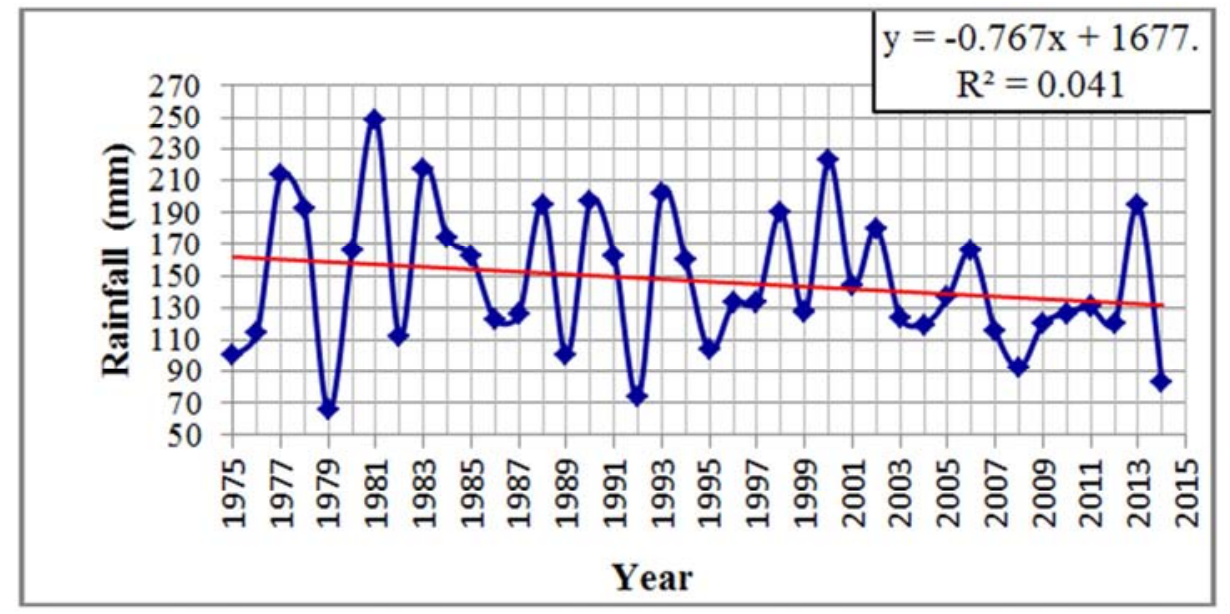

Figure 2. Pre-monsoon season mean rainfall of Bangladesh during 1975-2014. 


\subsection{Trend of Monsoon Season Rainfall}

The monsoon seasonal mean rainfall for the period 19752014 was found to be significantly unchanged. The result of the study for monsoon season mean rainfall is shown in figure 3 . The value of the mean rainfall of this season for different stations is found to be between $333 \mathrm{~mm}$ to $539 \mathrm{~mm}$ with standard deviations of $113 \mathrm{~mm}$ to $235 \mathrm{~mm}$. BMD declared that the normal rainfall of that season was $430 \mathrm{~mm}$ in 2014, whereas this study has found $434 \mathrm{~mm}$ in 2014. The analysis of this study reveals that the average rainfall of the study are highly lowest from normal rainfall in the monsoon season in years 1975, 1980, 1989, 1992, 1994, 2006, 2010, 2012 and 2013. It is seen from analysis that the linear trend line shows almost same for every year.

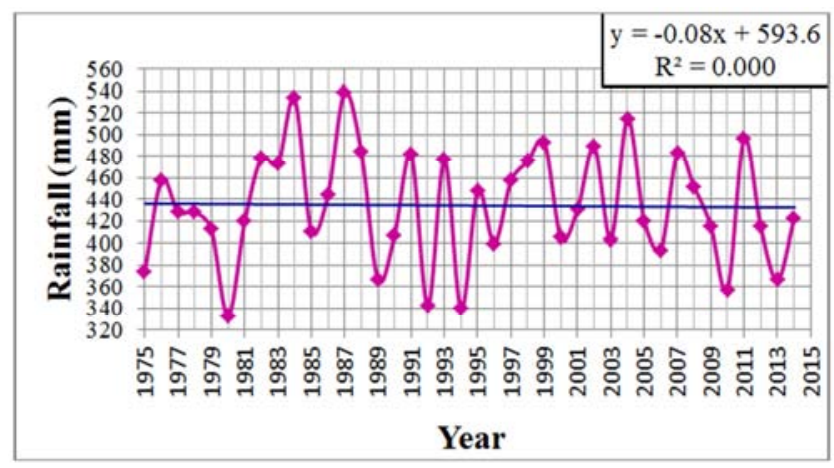

Figure 3. Monsoon season mean rainfall of Bangladesh during 1975-2014.

\subsection{Trend of Post-Monsoon Season Rainfall}

The mean rainfall for the post-monsoon season of Bangladesh in the study is shown in Figure 4. The mean rainfall of this season for different stations is found to be between $27 \mathrm{~mm}$ to $201 \mathrm{~mm}$ with standard deviations of 23 $\mathrm{mm}$ to $127 \mathrm{~mm}$. According to BMD (2014), the average normal rainfall of season was $101 \mathrm{~mm}$. The analyses of data for this season indicates that the average rainfall was highly lowest from normal rainfall in years 1981, 1982, 1994, 1997, 2004, 2011 and 2014. Further, the analyses show that the rainfall variability and trend of all stations were increasing. The observed data and linear trend line shows the increasing trends of Post-monsoon mean rainfall of the Bangladesh at the rate of $0.012 \mathrm{~mm}$ per year.

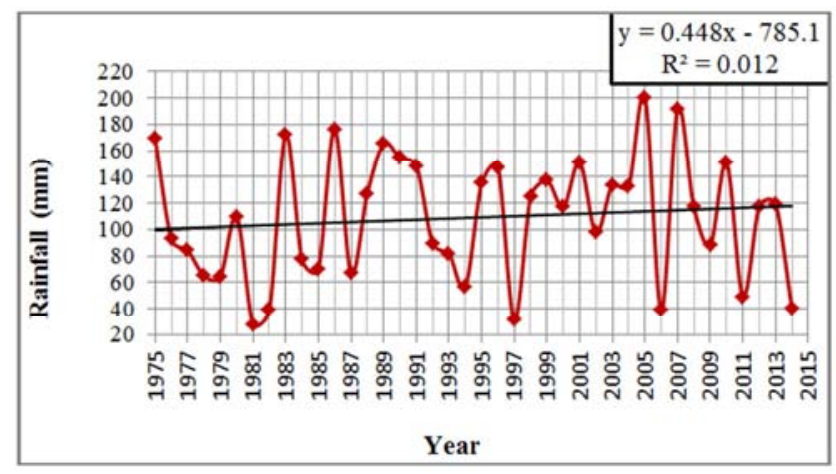

Figure 4. Post-monsoon season mean rainfall of Bangladesh during 1975 2014

\subsection{Trend of Winter Season Rainfall}

The mean rainfall of winter season over Bangladesh during 1975 to 2014 is shown in Figure 5. From the analyses it has been observed that the amounts of mean rainfall in winter for different stations are found to be between $1 \mathrm{~mm}$ to $33 \mathrm{~mm}$ with standard deviations of $2 \mathrm{~mm}$ to $20 \mathrm{~mm}$. In the year 2014, BMD declare that the annual average normal rainfall was $15 \mathrm{~mm}$. The analysis explores that the annual average rainfall was highly lowest from normal rainfall in years 1975, 1978, 1986, 1989, 2002, 2004, 2009, 2011, 2012 and 2013. It is seen from analysis that the rainfall variability and the trend of all stations under study are decreasing. The observed data and linear trend line show the decreasing trend of annual rainfall of the Bangladesh rate at $0.058 \mathrm{~mm}$ per year.

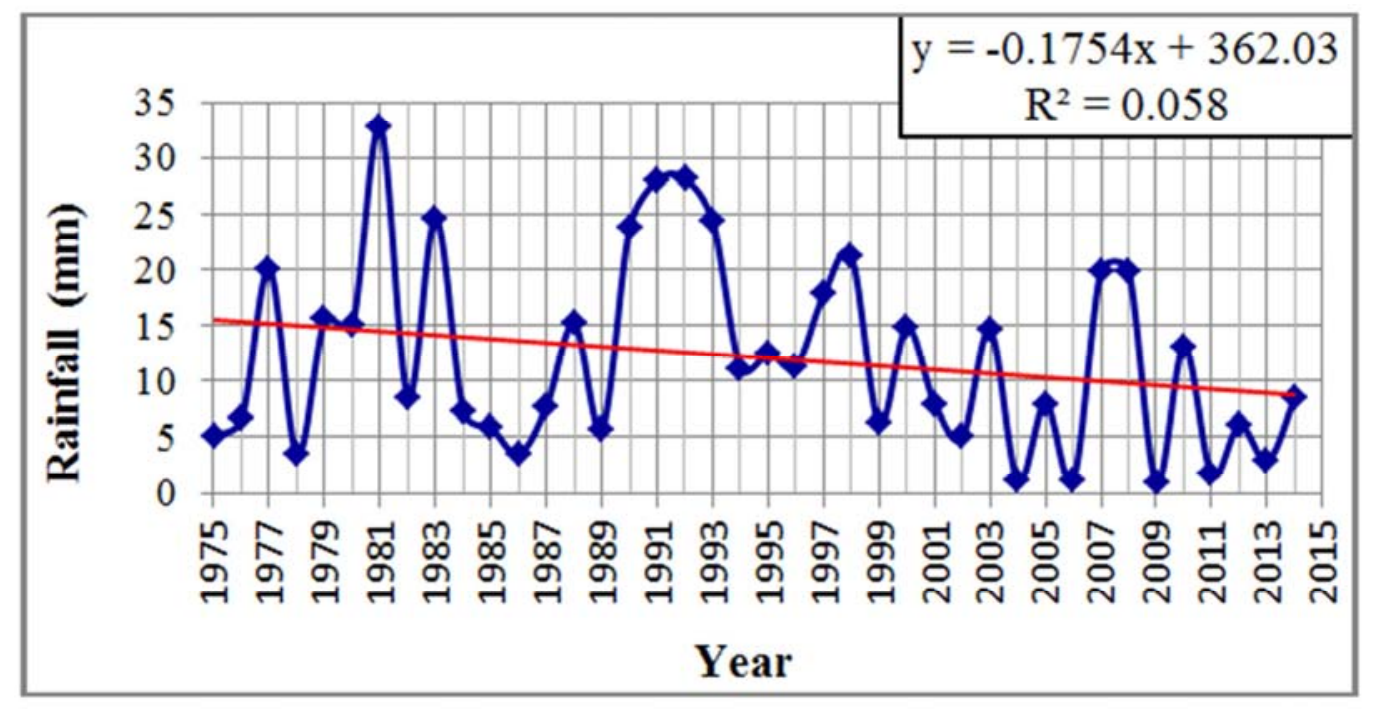

Figure 5. Winter season mean rainfall of Bangladesh during 1975-2014. 


\section{Conclusion}

Our prime objective was to examine the trend and rainfall variability. The regression models predict 31 rain gauge stations in Bangladesh for the period 1975-2014. We carefully checked the data before analyzing it. Although the data set we use in our study is known to be of high quality, we found quite a few numbers of spurious observations in it. This finding reemphasizes our concern of data quality. We estimated the mean rainfall with SD for annual, premonsoon, monsoon, post-monsoon. We noted that outliers in regression can severely affect the fitting of the model as their omission can turn a poorly fitted model to be a good model fitting. This finding also supports our view to use diagnostics in every step of regression fitting. In the study, the trend of rainfall in all season decreasing except postmonsoon. The annual rainfall decreasing trends of all stations are greater than those of the monsoon and other seasonal rainfall of these stations. The estimated linear trend reveals decreasing of mean rainfall which indicates a risk towards drought. However, careful cautions are warranted to interpret these findings as the study used secondary data. Despite these limitations, the findings are appreciable and may provide valuable information for climate related studies such as water resources planning, agricultural productions and drought or flood contingency services. Finally, it can be concluded that the rainfall is in a decreasing trend in recent years due to climate change and a sharp decreasing trend of rain over Bangladesh. The classification of rainfalls in a systematic way is therefore critical in order to take necessary actions toward drought mitigation and sustainable development.

\section{References}

[1] IPCC (2007) Climate Change 2007: Synthesis Report. In: R. K. Pachauri and A. Reisinger, Eds., Contribution of Working Groups I, II and III to the Fourth Assessment Report of the Intergovernmental Panel on Climate Change (IPCC), Cambridge University Press, Cambridge.

[2] IPCC (2007) Climate Change 2007: The Physical Science Basis. In: S. Solomon, D. Qin, M. Manning, Z. Chen, M. Marquis, K. B. Averyt, M. Tignor and H. L. Miller, Eds., Contribution of Working Group I to the Fourth Assessment Report of the Intergovernmental Panel on Climate Change (IPCC), Cambridge University Press, Cambridge.

[3] IPCC (2007) Climate Change 2007: Impacts, Adaptation and Vulnerability. In: M. L. Parry, O. F. Canziani, J. P. Palutikof, P. J. van der Linden and C. E. Hanson, Eds., Contribution of Working Group II to the Fourth Assessment Report of the Intergovernmental Panel on Climate Change (IPCC), Cambridge University Press, Cambridge.

[4] Joeri, R., William, H., Jason, H. L., van Vuuren, D. P., Keywan, R., Mathews, B. M., Tatsuya, H., Kejun, J. and Malte, M. (2011), "Emission Pathways Consistent with a $2^{\circ} \mathrm{C}$ Global Temperature Limit”, Nature Climate Change, Vol. 01, P. 413-418.

[5] Spencer, R. W. (2008), "The Discovery of Global Warming.
American Institute of Physics", Harvard University Press, Cambridge.

[6] Alamgir, M., S. Shahid, M. K. Hazarika, S. Nashrrullah, S. B. Harun, and S. Shamsudin, (2015), "Analysis of Meteorological Drought Pattern during Different Climatic and CroppingSeasons in Bangladesh", Journal of the American Water Resources Association (JAWRA), P. 1-13. DOI: 10.1111/jawr. 12276

[7] Devkota L. P. (2006), "Rainfall over SAARC region with special focus on tele-connections and long range forecasting of Bangladesh monsoon rainfall, monsoon forecasting with a limited area numerical weather prediction system", Report No-19, SAARC Meteorological Research Centre (SMRC), Dhaka, Bangladesh.

[8] Mannan M. A., M. A. M. Chowdhury and S. Karmakar (2016), " Prediction of Rainfall over Southeastern part of Bangladesh during Monsoon Season", International Journal of Integrated Sciences \& Technology, Vol. 2, P. 73-82.

[9] Imon, A. H. M. R, M. C. Roy and S. K. Bhattacharjee (2012), "Prediction of Rainfall Using Logistic Regression", PJSOR, Vol. 8, No. 3, P. 655-667.

[10] Nicholson, S. E. (2000), "The nature of rainfall variability over Africa on time scales of decades to millennia," Global and Planetary Change. Vol. 3, No. 26, P. 137-158.

[11] Nicholson, S. E. and J. P. Grist, (2001), "A conceptual model for understanding rainfall variability in the West African Sahel on interannual and interdecadal timescales", International Journal of Climatology, Vol. 21, No. 14, P. 1733-1757. doi: 10.1002/joc.648.

[12] Rodrigo, S., M. J. Esteban-Parra, D. Pozo-Va 'zquez and Y. Castro-D1'ez, (2000) "Rainfall variability in southern Spain on decadal to centennial time scales", International Journal of Climatology, Vol. 20, No. 7, P. 721-732.

[13] Rotstayn, L. D., Lohmann, Ulrike, (2002), “ Tropical rainfall trends and the indirect aerosol effect", Journal of Climate, Vol. 15, P. 2103-2116.

[14] Murphy, B. F., Timbal, Bertrand, (2007), “A review of recent climate variability and climate change in southeastern Australia", International Journal of Climatology, doi: 10.1002/joc. 1627 .

[15] Nicholls, N., Lavery, Beth, (2006), “Australian rainfall trends during the twentieth century", International Journal of Climatology, Vol. 12, No. 2, P. 153-163. doi: 10.1002/joc.3370120204.

[16] Islam, T., S. Saha, A. A. Evan, N. Halder, S. C. Dey, (2016), "Monthly Weather Forecasting through ANN Model: A Case Study in Barisal, Bangladesh", International Journal of Advanced Research in Computer and Communication Engineering, Vol. 5, No. 6, Copyright to IJARCCE DOI 10.17148/IJARCCE.2016.5601 1

[17] Rahman, M. R., M. Salehin, J. Matsumoto, (1997), “Trends of monsoon rainfall pattern in Bangladesh, Bangladesh Journal of Water Resources, Vol. 14, No. 18, P. 121-138.

[18] Shahid, S., (2009), "Rainfall variability and the trends of wet and dry periods in Bangladesh, International Journal of Climatology. 
[19] Ahmed, R. and S. Karmakar, (1993), "Arrival and withdrawal dates of the summer monsoonin Bangladesh", International Journal of Climatology, Vol. 13, P. 727.

[20] Islam, M. N. and H. Uyeda, (2008), "Use of TRMM in determining the climatic characteristics ofrainfall over Bangladesh, Remote Sensing of Environment, Vol. 108, No. 3, P. 264.

[21] McLachlan, G. J. and T. Krishnan, (1997), "The EM Algorithm and Extensions", Wiley, New York City, New York.
[22] Kannan, M., S. Prabhakaran and P. Ramachandran, (2013), "Rainfall Forecasting Using DataMining Technique", International Journal of Engineering and Technology, Vol. 2, No. 6, P. 397.

[23] Roy, M. (2013), “Time Series, Factors and Impacts Analysis of Rainfall in North-Eastern Part in Bangladesh", International Journal of Scientific and Research Publications, Vol 3, No. 8, P. 01. 